\title{
EFEKTIFITAS INSTALASI PENGOLAHAN AIR LIMBAH RUMAH SAKIT “X” KABUPATEN BANJAR
}

\author{
Arifin, Istiqamah, Sulaiman Hamzani \\ Jl.H.M.Cokrokusumo No.1A Kota Banjarbaru \\ Email : arifinmkes@gmail.com
}

\begin{abstract}
Effectivity of waste water treatment installations in Hospital's X Banjar Regency.Hospital's X has a wastewater treatment Installations which began operating from the year 2008 - until now. The system uses the wastewater treatment Installations processing system for aerobic and anaerobic biological in a wastewater treatment process using media hive of bees to do the filtering. In the media there is a biofilm that attached to the media hive of bees to help the process of decomposition of organic and inorganic materials. This research aims to know the performance of waste water treatment installations in Hospital's X Banjar Regency. This type of research is descriptive, i.e. describe the performance measurement quality by doing the wastewater treatment Installations for parameters $\mathrm{pH}$, temperature, BOD, COD, TSS, and free Ammonia (NH3-N) and compared with Regulation of South Kalimantan Governor number 04 in 2007 about the raw quality of liquid waste for the activities of the hospital. The research design used observation, interviews and measurements. Method of sampling used composite sampling. The results showed that the performance of the the wastewater treatment Installations at Hospital's X still hasn't been fullest measurement results from the laboratory, the value of the measurement of BOD, COD, TSS and Ammonia free still not qualify. This is due to the existence of problems on aerobic processing, bak bak bak pengendap end, chlorination and a monitoring that is the abundance of mud that settles in the base of the tub because it never done drain the mud. Efforts to improve the performance of the the wastewater treatment Installations i.e. preferably done drain sludge routinely on the bak-bak processing every 6 months, installing blower manual in aerobic processing and adds additional equalization tubs.
\end{abstract}

Keywords: Effectivity of the wastewater treatment Installations, waste water, hospital

\begin{abstract}
Abstrak: Efektifitas instalasi pengolahan air limbah di rumah sakit $\mathrm{X}$ Kabupaten Banjar. Rumah sakit " $X$ " memiliki Instalasi Pengolahan Air Limbah (IPAL) yang mulai beroperasi dari tahun 2008 - hingga sekarang. Sistem IPAL ini menggunakan sistem pengolahan biologis secara anaerob dan aerob yakni suatu proses pengolahan air limbah dengan menggunakan media sarang tawon untuk melakukan penyaringan. Di media tersebut terdapat biofilm yang melekat dibagian media sarang tawon untuk membantu proses penguraian bahan organik dan anorganik. Penelitian ini bertujuan untuk mengetahui kinerja instalasi pengolahan air limbah di rumah sakit "X" Kabupaten Banjar. Jenis penelitian ini bersifat deskriptif, yaitu menggambarkan kinerja IPAL dengan melakukan pengukuran kualitas air limbah untuk parameter $\mathrm{pH}$, suhu, BOD, COD, TSS, dan Amonia bebas $\left(\mathrm{NH}_{3}-\mathrm{N}\right)$ dan dibandingkan dengan Peraturan Gubernur Kalimantan Selatan Nomor 04 Tahun 2007 tentang Baku Mutu Limbah Cair bagi kegiatan rumah sakit. Desain penelitian yang digunakan observasi, wawancara dan pengukuran. Metode pengambilan sampel yang digunakan composite sampling.Hasil penelitian menunjukkan bahwa kinerja IPAL di ruamh sakit "X" masih belum maksimal, dari hasil pengukuran laboratorium, nilai pengukuran BOD, COD, TSS dan Amonia bebas masih belum memenuhi syarat. Hal ini dikarenakan adanya permasalahan pada bak pengolahan aerob, bak pengendap akhir, bak klorinasi dan bak monitoring yaitu banyaknya lumpur yang mengendap dibagian dasar bak dikarenakan tidak pernah dilakukan pengurasan lumpur. Upaya untuk meningkatkan kinerja IPAL yaitu sebaiknya dilakukan pengurasan lumpur
\end{abstract}


secara rutin pada bagian bak-bak pengolahan setiap 6 bulan sekali,memasang blower manual di bak pengolahan aerob dan menambah bak ekualisasi tambahan.

Kata kunci $\quad$ : Kinerja IPAL, Air limbah, Rumah Sakit

\section{PENDAHULUAN}

Rumah sakit merupakan sarana pelayanan masyarakat yang diperuntukkan bagi pelayanan umum tempat berkumpulnya orang sakit maupun orang sehat, atau menjadi tempat penularan penyakit serta memungkinkan terjadinya pencemaran lingkungan dan gangguan kesehatan. Untuk mengurangi risiko dan gangguan kesehatan tersebut maka perlu penyelenggaraan kesehatan lingkungan atau sanitasi lingkungan rumah sakit sesuai dengan persyaratan kesehatan seperti infeksi nosokomial, penyehatan ruang bangunan, pengendalian vektor dan pengendalian limbah rumah sakit. Pengawasan rumah sakit khususnya pembuangan air limbah perlu menjadi perhatian bersama agar tidak berpotensi untuk mencemari sumber air minum dan badan air penerima (1)

Limbah rumah sakit adalah semua limbah atau sampah yang dihasilkan dari kegiatan rumah sakit dan kegiatan penunjang lainnya. Secara umum limbah rumah sakit dibagi dalam dua kelompok besar, yaitu limbah medis dan non medis baik padat maupun cair. Limbah medis yaitu limbah infeksius, limbah jaringan tubuh, limbah sitotoksik, limbah farmasi, limbah kimia,dan limbah radioaktif. Sedangkan limbah non medis yaitu berasal dari kantor/administrasi (kertas), unit pelayanan (berupa karton, kaleng, botol), sampah dari ruang pasien, sampah dapur (sampah pembungkus, sisa makanan, sayur) (2).

Air limbah yang berasal dari kegiatan rumah sakit merupakan salah satu sumber pencemaran air yang sangat potensial. Hal ini disebabkan karena air limbah rumah sakit mengandung senyawa organik yang cukup tinggi juga kemungkinan mengandung senyawa-senyawa kimia lain, serta mikroorganisme patogen yang dapat menularkan penyakit terhadap masyarakat disekitarnya, maka dari itu air limbah rumah sakit harus dikelola dengan baik karena air limbah rumah sakit dapat berpengaruh besar terhadap lingkungan dan kesehatan diantaranya gangguan kenyamanan dan estetika, gangguan/kerusakan terhadap tanaman dan binatang, serta gangguan terhadap kesehatan manusia seperti gangguan genitik dan reproduksi. Oleh karena itu, setiap rumah sakit diharuskan mengolah air limbahnya sampai memenuhi persyaratan standar yang berlaku (3).

Masalah yang sering muncul dalam hal pengelolaan limbah rumah sakit adalah terbatasnya dana yang ada untuk membangun fasilitas pengolahan limbah serta biaya operasinya, khususnya untuk rumah sakit tipe kecil dan menengah. Suatu pengelolaan air limbah yang baik sangat dibutuhkan dalam mendukung hasil kualitas efluen sehingga tidak melebihi syarat baku mutu yang ditetapkan oleh pemerintah dan tidak menimbulkan pencemaran pada lingkungan sekitar. Oleh karena itu, pentingnya pengolahan air limbah rumah sakit, maka perlu mengetahui pengolahan air limbah rumah sakit yang akan di bahas pada karya tulis ilmiah ini (4).

Rumah Sakit "X"merupakan Rumah Sakit Umum Daerah milik Pemerintah Kebupaten Banjar yang secara teknis bertanggung jawab kepada Dinas Kesehatan Kabupaten Banjar dan operasionalnya bertanggung jawab kepada Bupati Banjar. Rumah Sakit "X" merupakan rumah sakit kelas B.

Hasil penelitian Ramadana tahun 2011 di RSUD X dengan melakukan pengukuran kualitas air limbah diperoleh hasil yaitu suhu $28^{\circ} \mathrm{C}, \mathrm{pH} 7$, BOD $34,4 \mathrm{mg} / \mathrm{l}$, COD 134,9 mg/l, TSS 36,4 mg/l, $\mathrm{NH}_{3}$ 2,8mg/ldan MPN Coliform 16.000 kuman/100 ml sampel, jika hasil tersebut dibandingkan dengan baku mutu limbah cair menurut KEPMENLH RI No. 58/MENLH/12/1995 dengan parameter suhu $30{ }^{\circ} \mathrm{C}$, pH 6 - 9, BOD $30 \mathrm{mg} / \mathrm{l}$, COD 80 $\mathrm{mg} / \mathrm{l}$, TSS $80 \mathrm{mg} / \mathrm{l}, \mathrm{NH}_{3}$ 0,1 mg/l, dan MPN Coliform 10.000 kuman/100 ml sampel, 
maka dapat disimpulkan, masih ada parameter yang belum memenuhi syarat seperti BOD, COD, $\mathrm{NH}_{3}$, dan MPN Coliform.Saran dari penelitian tersebut juga belum direalisasi oleh pihak rumah sakit seperti melakukan perawatan terhadap unit-unit IPAL, membersihkan seluruh bagian area sistem IPAL, dan meningkatkan pengawasan terhadap kualitas air limbah yang diolah (5).

Hasil pengukuran air limbah yang dilakukan oleh pihak Rumah Sakit pada tahun 2014 masih ada parameter pemeriksaan yang belum memenuhi syarat. Baku mutu limbah cair yang digunakan yaitu menurut Peraturan Gubernur Kal-Sel No. 04 tahun 2007 tentang baku mutu limbah cair bagi kegiatan rumah sakit yaitu dengan kadar maksimum suhu $30^{\circ} \mathrm{C}$, $\mathrm{pH} 6$ 9, BOD $30 \mathrm{mg} / \mathrm{l}$, COD $80 \mathrm{mg} / \mathrm{l}$, TSS $30 \mathrm{mg} / \mathrm{l}$, $\mathrm{NH}_{3}$ 0,1 mg/l, Poshpat $2 \mathrm{mg} / \mathrm{l}$. Berikut hasil pemeriksaan pada bulan Desember 2014 yaitu pH 6,7, BOD 32,4 mg/l, COD 100,6 $\mathrm{mg} / \mathrm{l}$, TSS $22 \mathrm{mg} / \mathrm{l}$, dan Posphat 1,98 mg/l (6).

Proses pengolahan air limbah di RSUD saat ini memiliki lima unit bakpengolahan untuk mengolah air limbah hasil kegiatan rumah sakit, yakni bak pengumpul (screening), bak ekualisasi, bak pengolahan anaerob-aerob, bak klorinasi, dan bak monitoring.

Sejak IPAL dioperasikan pada tahun 2007hingga sekarang tahun 2015 belum pernah ada studikhusus untuk mengkaji kinerja proses dan sistem IPAL di RSUD ini.

Tujuan penelitian ini adalah mengetahui efektifitas instalasi pengolahan air limbah di BLUD RSUD "X" Kabupaten Banjar meliputi sumber kegiatan yang menghasilkan air limbah, volume air limbah, dimensi bak pengolahan air limbah, tahapan pengolahan air limbah, cara operasional dan pemeliharaan IPAL, lama kontak pada tiap pengolahan air limbah, kualitas air limbah pada tiap-tiap bak pengolahan air limbah dan efektifitas pengolahan air limbah.

\section{BAHAN DAN CARA PENELITIAN}

Desain penelitian adalah observasional dengan menggunakan studi cross sectional. Penelitian dilakukan di rumah sakit "X" Kabupaten Banjar. Populasi dalam penelitiaan ini adalah keseluruhan air limbah yang dikeluarkan dari kegiatan ruangan pada rumah sakit " $X$ ". Pengambilan sampel air limbah dilakukan sebanyak empat kali dalam waktu yang berbeda dan dilakukan pengulangan 2 hari, pengambilan sampel dengan metode composite sampling.Titik pengambilan sampel air limbah dilakukan pada bak pengumpul 1 (inlet), bak ekualisasi, bak pengendap awal, bak klorinasi, bak monitoring dan selokan (outlet).

Pengumnulan data diperoleh melaluiwawancara kepada penanggung jawab IPAL rumah sakit, dilakukan pengamatan langsung pada objek penelitian menggunakan panduan observasi dan pemeriksaan sampel di lapangan terhadap parameter $\mathrm{pH}$, dan suhu. Pemeriksaan di laboratorium kimia lingkungan terhadap parameterBOD, COD, TSS, dan Amonia bebas $\left(\mathrm{NH}_{3}-\mathrm{N}\right)$.

Data yang telah terkumpul kemudian diolah secara manual, dianalisis secara deskriptif dan dibandingkan dengan Peraturan Gubernur Kalimantan Selatan No. 04 Tahun 2007 dan teori-teori yang berhubungan dengan penelitian.untuk mengetahui efektifitas IPAL. Rumus yang digunakan yaitu :

$E=\frac{\text { Inf-efl }}{\text { inf }} \times 100 \%$.

(Metcalf dan Eddy, 1991)

Keterangan :

E : Efektifitas pengolahan air limbah (IPAL)

Inf : Kualitas influent air limbah rumah sakit untuk parameter $\mathrm{pH}$, suhu, BOD, COD, TSS, dan Amonia bebas $\left(\mathrm{NH}_{3}-\mathrm{N}\right)$.

Efl : Kualitas effluent air limbah rumah sakit untuk parameter $\mathrm{pH}$, suhu, BOD, COD, TSS, dan Amonia bebas $\left(\mathrm{NH}_{3}-\mathrm{N}\right)$.

\section{HASIL DAN PEMBAHASAN}

Instalasi Pengolahan Air Limbah (IPAL) yang digunakan oleh pihak rumah sakit yaitu menggunakan Biofilter anaerobaerob. Dalam kondisi normal, kapasitas IPAL rumah sakit mampu mengolah air limbah sebanyak $15 \mathrm{~m}^{3} /$ hari. Mesin IPAL bekerja secara otomatis, akan tetapi pada saat penelitian ini dilakukan tidak berfungsi lagi sebagaimana mestinya, dan mesin yang digunakan sekarang untuk 
membantu kelancaran proses pengolahan air limbah rumah sakit dibantu dengan mesin genset. Pengolahan IPAL rumah sakit berlangsung selama 6 jam yaitu pukul 06.00 - 10.00 WITA dan pukul 14.00 16.00 WITA.

\section{Sumber air limbah}

Air limbah rumah sakit adalah seluruh buangan cair yang berasal dari hasil proses semua kegiatan rumah sakit yang meliputi limbah domestik cair yakni buangan kamar mandi, dapur, dan air bekas pencucian pakaian, sedangkan limbah cair klinis yakni air limbah yang berasal dari kegiatan klinis rumah sakit misalnya air bekas cucian luka, cucian darah, limbah yang berasal dari laboratorium dan lainnya. Air limbah buangan rumah sakit yang berasal dari buangan limbah cair domestik maupun limbah cair klinis umumnya mengandung senyawa polutan organik yang cukup tinggi dan dapat diolah dengan proses pengolahan secara biologis, sedang air limbah yang berasal dari laboratorium dipisah dan ditampung, kemudian diolah secara fisika dan kimia, selanjutnya air olahannya dialirkan bersama-sama dengan air limbah yang lain dan diolah secara biologis (7).

Pada proses dilapangan, sumber air limbah yang berasal dari ruang laboratorium, operasi, laundry yang mengandung senyawa kimia, logam berat, bahan anorganik yang tinggi langsung melalui proses fisika dan biologis, seharusnya setelah proses fisika dilakukan pengolahan secara kimia terlebih dahulu, agar kandungan senyawa kimia, logam berat dan bahan anorganik yang tinggi dapat diturunkan. Berdasarkan hasil pemeriksaan kualitas air limbah pada bak pengumpul, parameter COD sangat tinggi yaitu 588,6 mg/l.

Berdasarkan hasil observasi, air sisa buangan dari kegiatan RSUD ini dari semua ruangan, WC dan kamar mandi, air limbah dimasukkan kedalam bak kontrol setelah itu disalurkan ke IPAL termasuk air hujan. Jumlah bak kontrol keseluruhan sebanyak 60 buah bak kontrol. Menurut Said N.I (1999) saluran air hujan sebaiknya diolah terpisah dengan saluran pembuangan air limbah yang menuju ke IPAL dan air hujan langsung dibuang kesaluran umum (riol kota) (7).
2. Volume air limbah.

Dimensi bak pengolahan dan lama kontak pengolahan air limbah.Jumlah air bersih yang dibutuhkan per orang akan mempengaruhi jumlah air limbah yang dibuang. Menurut Naoko (2005) umumnya berkisar 60 - $70 \%$ per hari dari banyaknya air bersih yang dibutuhkan (8).

Pemakaian air bersih di rumah sakit ini, berdasarkan rekening PDAM pada bulan Februari 2015 diperoleh data adalah 4.250 $\mathrm{m}^{3}$ /bulan. Jika diasumsikan dengan pemakaian air bersih sebanyak $70 \%$ per orang per hari diperoleh data sebagai berikut : $\frac{4.250 \mathrm{~m} 3 / \text { bulan }}{30 \text { hari }}=141,6 \mathrm{~m}^{3} /$ hari $\times 70$ $\%=99 \mathrm{~m}^{3} /$ hari $=4 \mathrm{~m}^{3} / \mathrm{jam}$. Sedangkan menurut Soedjarwo (2003) dengan perhitungan jumlah bed yaitu 600 lt $/$ bed $/$ hari $\times 230$ bed $=138.000$ liter $/$ hari atau $138 \mathrm{~m}^{3} /$ hari.

Jika dihubungkan dengan total volume bak pengolahan air limbah secara keseluruhan yaitu 48,47 $\mathrm{m}^{3}$ dapat dikatakan bahwa jumlah volume air limbah yang dihasilkan tidak sebanding dengan kapasitas bak. Sehingga lama kontak pengolahan air limbah diperoleh :

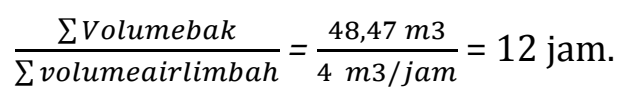

Dari hasil perhitungan, waktu kontak proses pengolahan yang optimal diperoleh 12 jam, sedangkan 12 jam lagi tidak terolah dengan maksimal. Hal ini dikarenakan kapasitas bak tidak sebanding dengan jumlah air limbah yang dihasilkan perharinya.

Waktu tinggal setiap bak pengolahan sangat mempengaruhi hasil air olahan, semakin lama waktu tinggal yang dibutuhkan, maka efisiensi penurunan kadar setiap parameter semakin tinggi. Berdasarkan literatur yang didapat, waktu tinggal pada setiap bak pengolahan bervariasi, menurut Said (2006) dengan beban permukaan $20-50 \mathrm{~m}^{3} /$ hari, waktu tinggal yang dibutuhkan pada bak pengendap awal 3 - 5 jam, bak pengolahan anaerob-aerob $6-8$ jam, dan bak pengendap akhir $2-5$ jam. Sedangkan dengan beban permukaan $150 \mathrm{~m}^{3} /$ hari, waktu tinggal yang dibutuhkan pada bak pengumpul dan bak ekualisasi $4-8$ jam, 
bak pengendap awal 2 - 4 jam, bak pengolahan anaerob 9 jam, bak pengolahan aerob 5,6 jam dan bak pengendap akhir 3,2 jam, jika dijumlahkan waktu tinggal keseluruhan yaitu 24 jam.

3. Tahapan pengolahan air limbah dan kualitas air limbah

a. Bak pengumpul

Air limbah yang berasal dari semua ruangan dan dimasukkan ke dalam bak kontrol lalu dialirkan kembali ke bak pengumpul. Bak pengumpul merupakan pengolahan pendahuluan (pre treatment) pada bak pengolahan limbah. Menurut Sugiharto (1987) sebelum memasuki proses pengolahan, perlu dilakukan pembersihan agar mempercepat kinerja pengolahan selanjutnya. Tujuan dari pengolahan pendahuluan yaitu untuk mensortir kerikil, menghilangkan zat padat, memisahkan lemak, dan mengurangi jumlah lumpur yang masuk ke bak ekualisasi (9).

Berdasarkan hasil pemeriksaan kualitas air limbah pada bak pengumpul 1, parameter $\mathrm{pH}$, suhu dan BOD telah memenuhi baku mutu limbah cair, sedangkan parameter COD, TSS dan Amonia bebas $\left(\mathrm{NH}_{3}-\mathrm{N}\right)$ masih belum memenuhi baku mutu limbah cair, hal ini dikarenakan pada bak pengumpul 1 merupakan proses awal sebelum pengolahan.

Pemeriksaan kualitas air limbah pada bak pengumpul 2 hanya parameter $\mathrm{pH}$ dan suhu yang telah memenuhi baku mutu limbah cair, sedangkan parameter BOD, COD, TSS dan Amonia bebas $\left(\mathrm{NH}_{3}-\mathrm{N}\right)$ belum memenuhi baku mutu limbah cair. Pada parameter $\mathrm{pH}$ di bak pengumpul 2 tidak terjadi peningkatan ataupun penurunan, sedangkan suhu terjadi penurunan yaitu dari $28,25^{\circ} \mathrm{C}$ turun menjadi $28,12{ }^{\circ} \mathrm{C}$. Hal ini bisa disebabkan pada proses pengambilan sampel dengan waktu yang berbeda-beda. Pada parameter BOD, nilai BOD pada bak pengumpul 1 yaitu $25 \mathrm{mg} / \mathrm{l}$, sedangkan pada bak pengumpul 2 nilai BOD naik menjadi $105 \mathrm{mg} / \mathrm{l}$. Fluktuasi yang terjadi pada nilai BOD disebabkan karena waktu tinggal yang cukup lama yaitu 20 jam, sehingga terjadi proses biologis pada bak pengumpul 2. Untuk parameter COD dari bak pengumpul 1 ke bak pengumpul 2 terjadi penurunan walaupun tidak signifikan yaitu dari 588,6 $\mathrm{mg} / \mathrm{l}$ turun menjadi 559,7 mg/l, hal ini disebabkan terjadinya proses biologis dan pengendapan lumpur, sehingga nilai COD menjadi turun. Pada parameter TSS dari bak pengumpul 1 ke bak pengumpul 2 terjadi penurunan yang cukup signifikan yaitu dari $762 \mathrm{mg} / \mathrm{l}$ turun menjadi 212,5 $\mathrm{mg} / \mathrm{l}$, hal ini dikarenakan waktu tinggal yang cukup lama sehingga proses pengendapan bekerja dengan maksimal. Untuk parameter Amonia bebas $\left(\mathrm{NH}_{3}-\mathrm{N}\right)$ terjadi peningkatan dari bak pengumpul 1 ke bak pengumpul 2 yaitu $15,39 \mathrm{mg} / \mathrm{l}$ naik menjadi $15,41 \mathrm{mg} / \mathrm{l}$, hal ini disebabkan terjadinya proses biologis pada bak pengumpul 2 yaitu proses dekomposisi senyawa organik yang menimbulkan konsentrasi amonia menjadi naik.

Menurut Said (2006) waktu tinggal yang dibutuhkan pada bak pengumpul yaitu 4 - 8 jam, sedangkan kondisi dilapangan yaitu 20 jam, hal ini membuktikan bahwa bak pengumpul sudah berfungsi sebagaimana mestinya, sehingga parameter yang berperan di bak pengumpul seperti TSS terjadi penurunan yang cukup signifikan (10).

b. Bak ekualisasi

Air limbah dari bak pengumpul 2 disedot kedalam bak ekualisasi. Menurut Soeparman dan Suparmin (2001) tujuan dari proses ekualisasi adalah untuk meminimkan aliran yang akan masuk ke pengolahan selanjutnya, dan mengontrol $\mathrm{pH}$ agar memberikan kondisi optimum pada proses pengolahan selanjutnya (11). Pada proses ini diharapkan terjadinya penurunan pada parameter BOD dan TSS (12).

Hasil pemeriksaan kualitas air limbah pada ekualisasi hanya parameter $\mathrm{pH}$ dan suhu yang memenuhi baku mutu limbah cair, sedangkan parameter BOD, COD, TSS dan Amonia bebas $\left(\mathrm{NH}_{3}-\mathrm{N}\right)$ masih belum memenuhi baku mutu limbah cair. Ratarata nilai BOD, COD, dan TSS pada bak ekualisasi terjadi penurunan yaitu BOD 95 mg/l, COD 386 mg/l, dan TSS 109 mg/l, hal ini dikarenakan bak ekualisasi berdasarkan fungsinya tidak hanya menstabilkan aliran, tetapi juga menekan fluktuasi perubahan kandungan senyawa organik sehingga pada bak ekualisasi sudah berfungsi dengan baik, sedangkan parameter Amonia bebas $\left(\mathrm{NH}_{3}\right.$ $\mathrm{N})$ tidak ada terjadi peningkatan ataupun 
penurunan, hal ini dikarenakan tidak ada proses biologis yang terjadi pada bak ekualisasi.

c. Bak pengendap akhir

Pada proses permulaan pada bak pengolahan anaerob-aerob, sebelumnya harus melalui tahapan pada bak pengendap awal terlebih dahulu, proses yang terjadi pada bak pengendap awal yaitu pengendapan lumpur yang masih tersisa dari proses sebelumnya, pada bak pengendap awal diharapkan terjadinya penurunan parameter TSS dan waktu tinggal yang dibutuhkan yaitu $2-4$ jam (10).Proses yang terjadi dilapangan, waktu tinggal pada bak pengendap awal tidak sesuai dengan yang seharusnya, hal ini disebabkan karena jumlah air limbah yang dihasilkan terlalu banyak, dan proses pengolahan tidak bekerja dengan maksimal.

Pada bak pengolahan selanjutnya yaitu pengolahan anaerob, yaitu terjadinya proses penguraian limbah secara anaerob atau tanpa oksigen bebas oleh bakteri anaerobik atau fakultatif aerobik yang hidup menempel pada biofilter, mikroorganisme inilah yang akan menguraikan zat organik yang belum sempat terurai pada bak pengendap awal. Pada proses ini akan terjadi peningkatan pada parameter BOD, COD, dan Amonia (12).

Waktu tinggal yang dibutuhkan pada bak pengolahan anaerob yaitu 9 jam, sedangkan keadaan dilapangan waktu tinggal pada bak pengolahan anaerob sangat singkat, sehingga proses pengolahan tidak bekerja dengan maksimal (10).

Pada bak pengolahan aerob yaitu limbah diurai oleh bakteri yang melekat pada media biofilter dan diberi oksigen agar mempercepat proses penguraian sehingga dapat mengurangi BOD, COD dan Amonia (12).

Keadaan di lapangan, proses yang terjadi pada bak pengolahan aerob tidak lagi menggunakan blower dikarenakan mesin IPAL otomatis masih belum dilakukan perbaikan. Jika proses yang terjadi tidak sesuai dengan sebagaimana mestinya, maka proses penguraian bahan organik dan anorganik juga tidak bekerja dengan maksimal, sehingga parameter BOD, COD, dan Amonia bebas $\left(\mathrm{NH}_{3}-\mathrm{N}\right)$ seharusnya turun, kemungkinan besar terjadi peningkatan, dikarenakan tidak ada penambahan oksigen, sehingga bakteri yang mengurai bahan organik menjadi mati karena kekurangan oksigen yang menyebabkan kandungan bahan organik masih belum terurai secara sempurna, disamping itu juga karena jumlah air limbah yang dihasilkan tidak sesuai dengan kapasitas bak pengolahan, sehingga debit aliran pengolahan menjadi cepat, waktu tinggal yang dibutuhkan menjadi sedikit, jadi hasil air olahan tidak sesuai yang diharapkan.

Air hasil olahan setelah melalui proses pengolahan secara anaerob-aerob, air limbah langsung dialirkan ke bak pengendap akhir. Proses yang terjadi pada bak pengendap akhir yaitu pengendapan lumpur secara gravitasi. Dari hasil gabungan pengolahan ini, diharapkan terjadinya penurunan pada parameter BOD, COD, TSS, dan Amonia bebas $\left(\mathrm{NH}_{3}-\mathrm{N}\right)(2)$.

Adapun hasil pemeriksaan kualitas air limbah pada bak pengendap akhir, nilai rata-rata $\mathrm{pH}$, suhu dan Amonia bebas $\left(\mathrm{NH}_{3}\right.$ $\mathrm{N})$ terjadi penurunan, sedangkan parameter BOD, COD, dan TSS terjadi peningkatan yang cukup signifikan. Turunnya nilai $\mathrm{pH}$ pada bak pengendap akhir disebabkan terjadinya proses penguraian bahan-bahan organik dan anorganik yang kemudian membebaskan $\mathrm{CO}_{2}$ yang menyebabkan air limbah menjadi asam, sehingga kondisi ini masih dalam tahap normal. Sedangkan turunnya nilai suhu bisa disebabkan karena kebutuhan oksigen yang didalam air limbah berkurang dikarenakan bakteri pengurai membutuhkan pasokan oksigen lebih banyak, sehingga temperatur air limbah menjadi turun, sedangkan proses yang terjadi dilapangan tidak ada pemberian oksigen, hal ini yang menyebabkan bakteri pengurai cepat mati dikarenakan tidak bisa hidup karena kekurangan oksigen. Dampak dari matinya mikroorganisme pengurai akan menyebabkan kandungan BOD, COD, TSS dan Amonia yang masih tinggi. Untuk parameter BOD, COD, dan TSS terjadi peningkatan yang cukup signifikan, hal ini disebabkan karena blower untuk pemasok oksigen tidak berfungsi, jadi proses yang terjadi pada bak aerob hampir sama dengan 
anaerob yaitu hanya terjadi penguraian bahan organik dengan oksigen bebas, sedangkan bakteri membutuhkan oksigen terikat untuk mengikat senyawa-senyawa yang masih belum sempat terurai dari hasil pengolahan bak anaerob, jadi ketahanan kehidupan bakteri menjadi sedikit yang menyebabkan proses penguraian tidak bekerja dengan maksimal, sehingga akibatnya air limbah yang masih dalam penguraian terlihat keruh, selain dari hasil penguraian tidak maksimal yang menyebabkan nilai TSS tinggi yaitu disebabkan karena tidak pernah dilakukan pengurasan lumpur dan waktu tinggal yang dibutuhkan pada bak pengendap akhir yang sangat singkat dikarenakan air limbah yang masuk ke IPAL tidak sesuai dengan kapasitas bak pengolahan, sehingga debit aliran air limbah menjadi cepat. Untuk Amonia bebas $\left(\mathrm{NH}_{3}-\mathrm{N}\right)$ terjadi penurunan, hal ini disebabkan pada saat proses pengambilan, terjadinya pemberian air kaporit pada air limbah, sehingga dapat mereduksi amonium dengan baik.

d. Bak klorinasi

Air limpasan dari bak pengendap akhir langsung dialirkan ke bak klorinasi. Proses yang terjadi pada bak klorinasi yaitu pemberian air kaporit yang berfungsi untuk membunuh mikroorganisme patogen yang ada pada air limbah sebelum dialirkan ke badan air atau sungai (13).

Pada proses klorinasi diharapkan terjadinya penurunan pada parameter BOD, COD, dan Amonia bebas ( $\left.\mathrm{NH}_{3}-\mathrm{N}\right)$ (12).

Adapun hasil pengukuran kualitas air limbah, rata-rata nilai $\mathrm{pH}$ dan suhu terjadi peningkatan dibandingkan dengan ratarata $\mathrm{pH}$ dan suhu pada bak pengolahan sebelumnya. Naiknya nilai $\mathrm{pH}$ bisa disebabkan proses pemberian air kaporit ke air limbah, dimana sifat dari air kaporit adalah basa, sehingga kondisi $\mathrm{pH}$ pada bak klorinasi tetap dipertahankan menjadi 7 , sedangkan suhu meningkat bisa disebabkan pengaruh lingkungan dimana kondisi bak klorinasi pada posisi terbuka, sehingga temperatur lingkungan mempengaruhi temperatur air limbah.

Untuk parameter BOD, COD terjadi penurunan yang cukup signifikan. Hal ini bisa disebabkan karena terjadinya proses pemberian air kaporit, klor yang terdapat didalam air dalam kombinasi dengan amonia bisa didefinisikan sebagai klor terikat (14).

Klor terikat ini akan ikut mengikat senyawa organik yang masih terkandung didalam air hasil olahan, selain dari sifat klor, terjadinya pengocokan pada bak klorinasi, sehingga terjadi aerasi pada bak klorinasi, bak klorinasi juga pada posisi terbuka, hal ini bisa menyebabkan terjadinya fotosentesis yaitu masuknya sinar matahari kedalam air limbah, sehingga terjadi proses penguraian bahan organik didalam bak klorinasi.

Parameter TSS terjadi peningkatan, hal ini bisa disebabkan pemberian kaporit kedalam air limbah, sehingga air limbah menjadi keruh, sedangkan parameter Amonia bebas $\left(\mathrm{NH}_{3}-\mathrm{N}\right)$ terjadi peningkatan, hal ini bisa disebabkan terjadinya proses pengocokan pada bak klorinasi, pengocokan yang dibantu dengan baffle atau sekat yang terdapat banyak ganggang atau lumut, kemungkinan klor yang terkandung didalam air limbah menjadi berkurang, selain dari itu proses yang kemungkinan terjadi pada bak klorinasi yaitu penguraian bahan organik, hal ini bisa menyebabkan kadar Amonia menjadi meningkat, karena proses beodegradasi protein dan hasil proses anaerobik yang larut dalam air limbah.

e. Bak monitoring

Air limbah yang keluar dari bak klorinasi selanjutnya dialirkan ke bak monitoring. Air limbah yang masuk ke bak monitoring langsung dibuang ke selokan. Hasil pengukuran kualitas air limbah, ratarata nilai $\mathrm{pH}$ dan suhu masih dalam keadaan stabil tidak terjadi peningkatan ataupun penurunan, sedangkan parameter BOD dan Amonia bebas $\left(\mathrm{NH}_{3}-\mathrm{N}\right)$ terjadi penurunan. Hal ini bisa disebabkan proses yang terjadi pada bak monitoring yaitu terjadinya pengendapan secara gravitasi, sehingga bisa saja terjadinya penurunan amonia. Namun pada parameter COD dan TSS malah terjadi peningkatan. Hal ini bisa disebabkan karena jarak pipa pembuangan air limbah ke selokan yang terlalu jauh dan belum pernah dilakukan pengurasan lumpur pada bak monitoring.

4. Cara operasional dan Pemeliharaan IPAL

Cara pengoperasian IPAL di rumah sakit ini menggunakan mesin genset. Letak 
mesin genset terletak diluar diatas bak pengumpul, pipa penyedot mesin genset terletak pada bak pengumpul 2, posisi letak pipa penyedot didasar bak. Pada pengoperasian ini sangat mempengaruhi proses pengolahan air limbah pada tiap bak pengolahan, dengan menggunakan genset, debit air limbah yang masuk ke bak ekualisasi dan bak selanjutnya menjadi cepat, sehingga waktu tinggal pada setiap bak pengolahan tidak sesuai dengan yang seharusnya, selain itu juga letak pipa penyedot didasar bak sangat berpengaruh, karena kemungkinan besar lumpur yang ada didasar bak ikut tersedot ke bak ekualasasi. Hal ini bisa berdampak terhadap kualitas air limbah yang dihasilkan. Berdasarkan hasil pemeriksaan kualitas air limbah, air limbah hasil olahan terjadi peningkatan pada bak pengolahan anaerobaerob, hal ini disebabkan waktu tinggal pada tiap bak pengolahan yang terlalu singkat. Pada proses disenfeksi atau klorinasi, jumlah kaporit yang digunakan perharinya sebanyak $1 \mathrm{~kg}$ dengan jumlah air 200 liter. Jika dibandingkan dengan jumlah air limbah yang dihasilkan perharinya yaitu $99 \mathrm{~m}^{3}$, dosis klor yang digunakan sangat sedikit. Hal ini bisa mempengaruhi kualitas hasil air olahan.

Pemeliharaan IPAL yang dilakukan oleh pihak rumah sakit yaitu hanya membersihkan sampah besar yang terdapat pada bak pengumpul dengan melakukan penyaringan secara manual, sedangkan pengurasan lumpur pada bak pengendap akhir, bak klorinasi dan bak monitoring belum pernah dilakukan pengurasan, hal ini yang menyebabkan kualitas hasil olahan pada parameter TSS masih tinggi.

5. Efektifitas pengolahan air limbah

Berdasarkan hasil perhitungan efektifitas pengolahan air limbah yaitu dengan rumus $\frac{\operatorname{Inf}-\text { eff } x 100 \%}{\text { inf }}$ (Metcalf dan Eddy, 1991), efektifitas pengolahan pada parameter suhu sebesar 0,46\%, BOD -58,33 $\%$, COD 40,98 \%, TSS 73,33 \% dan Amonia bebas $\left(\mathrm{NH}_{3}-\mathrm{N}\right)-0,26 \%$. Pada parameter BOD terjadi peningkatan cukup signifikan, hal ini disebabkan pada bak pengolahan anaerob-aerob tidak bekerja dengan maksimal dikarenakan waktu tinggal pada tiap bak pengolahan yang terjadi dilapangan tidak sesuai dengan yang diharapkan. Sedangkan efisiensi penurunan parameter COD tidak terlalu terlalu besar, hal ini disebabkan karena air limbah yang berasal dari ruang laboratorium, ruang laundry, ruang operasi yang banyak mengandung senyawa kimia yang tinggi tidak dilakukan pengolahan secara kimia. Untuk efisiensi penurunan pada parameter TSS sangat besar yaitu 73,43 \%. Hal ini menunjukkan dalam penurunan TSS sudah bekerja dengan maksimal. Sedangkan parameter Amonia bebas $\left(\mathrm{NH}_{3}-\mathrm{N}\right)$ terjadi peningkatan walaupun terlalu besar, hal ini disebabkan karena pemberian klor yang tidak sesuai dengan jumlah air limbah yang dihasilkan, sehingga efisiensi dalam penurunan Amonia bebas $\left(\mathrm{NH}_{3}-\mathrm{N}\right)$ tidak sesuai dengan yang diharapkan.

\section{KESIMPULAN DAN SARAN}

Sumber air limbah rumah sakit "X" bersumber dari semua ruangan yaitu instalasi gizi, farmasi, rehabilitasi medik, haemodialisa, bedah sentral, rekam medik, IPRS, pemulasaran jenazah, instalasi sanitasi dan gedung, laboratorium, ruang operasi, instalasi gawat darurat (IGD), poli klinik, ruang perawatan, ruang radiologi, dan ruang bersalin.

Volume air limbahyang dihasilkan perharinya yaitu $99 \mathrm{~m}^{3} /$ hari atau $4 \mathrm{~m}^{3} / \mathrm{jam}$.

Dimensi bak pengolahan air limbah terdiri dari beberapa bak yaitu volume bak pengumpul (1) 1,65 $\mathrm{m}^{3}$, bak pengumpul (2) $3,78 \mathrm{~m}^{3}$, bak ekualisasi $8,97 \mathrm{~m}^{3}$, bak pengolahan anaerob-aerob $26,30 \mathrm{~m}^{3}$, bak klorinasi $6 \mathrm{~m}^{3}$, dan bak monitoring 1,60 $\mathrm{m}^{3}$.

Tahapan pengolahan air limbah mulai dari air limbah masuk kedalam bak kontrol dan langsung dialirkan menuju bak pengumpul, dari bak pengumpul disedot untuk dialirkan ke bak ekualisasi, setelah itu masuk ke bak pengendap awal, setelah itu masuk lagi ke bak pengolahan anaerob dan dialirkan kembali ke bak pengolahan aerob. Setelah dari bak pengolahan aerob, air limbah dialirkan ke bak klorinasi. Dari bak klorinasi, air limbah masuk ke bak monitoring.

Cara operasional dan pemeliharaan IPAL yaitu pengoperasian IPAL dilakukan dari pukul 06.00 - 10.00 WITA, dan pukul 
14.00 - 16.00 WITA. Untuk pemeliharaan IPAL, pihak RSUD Ratu Zalecha melakukan pembersihan sampah seperti dedaunan dan kotoran yang terdapat dalam bak pengumpul dan pengendap awal. 12 jam.

Lama kontak pada pengolahan yaitu

Kualitas air limbah dengan parameter $\mathrm{pH}$, suhu, BOD, COD, TSS dan Amonia bebas $\left(\mathrm{NH}_{3}-\mathrm{N}\right)$, hanya parameter $\mathrm{pH}$ dan suhu yang memenuhi standar baku mutu limbah cair bagi kegiatan rumah sakit yaitu Peraturan Gubernur Kalimantan Selatan No. 4 Tahun 2007, sedangkan parameter BOD, COD, TSS, dan Amonia bebas $\left(\mathrm{NH}_{3}-\mathrm{N}\right)$ melebihi standar baku mutu yang telah ditetapkan.

Efektifitas pengolahan air limbah dengan parameter COD dan TSS masih belum maksimal sedangkan parameter BOD dan Amonia bebas $\left(\mathrm{NH}_{3}-\mathrm{N}\right)$ terjadi peningkatan yang cukup signifikan. Saran yang dapat diberikan kepada pihak rumah sakit yaitu lakukan pengurasan lumpur secara rutin pada bagian bak-bak pengolahan setiap 6 bulan sekali, memasang blower manual di bak pengolahan aerob dan menambah bak ekualisasi tambahan.

\section{KEPUSTAKAAN}

1. Soedjarwo, 2003. Pengolahan Air Limbah Domestik, Rumah Sakit, dan Hotel. Pelatihan Dasar Teknologi Tepat Guna Pengolahan Air Limbah, Pusteklim, Yogyakarta.

2. Asmadi, 2013. Pengelolaan Limbah Medis Rumah Sakit, Gosyen, Yogyakarta.

3. Prassojo, F. Y, 2014. Pengelolaan Limbah Cair di Rumah Sakit Dirgahayu Kota Samarinda, Jurnal Baraja Niti, Volume 3 No. 4.

4. Mitabebi, 2012. Pengolahan Limbah Rumah Sakit. http://scribd.com/doc /104769690/Pengolahan-Limbah-

Rumah-Sakit. Diakses pada tanggal 17 Januari 2015.

5. Vianus, A. M, 2007. Optimalisasi Dosis Kaporit Untuk Identifikasi Bakteriologis MPN Coliform pada Limbah Cair di Outlet IPAL di RSUD
Ratu Zalecha Martapura Tahun 2007, Poltekkes Banjarmasin, Banjarbaru.

6. Zalecha, RSUD Ratu, 2014. Laporan Hasil Uji Laboratorium, BTKL, Martapura, pp: 1-2.

7. Said, N.I,1999.Teknologi Pengolahan Air Limbah Rumah Sakit dengan Sistem Biofilter Anaerob-Aerob, BBPT, Jakarta.

8. Naoko, Nakagawa. 2005. Sultability of Graywater Treatment for a Sustainability sanitation system. Procedings International Symposium on Ecohydrology.

9. Sugiharto, 1987. Dasar-Dasar Pengelolaan Air Limbah, Universitas Indonesia, Jakarta.

10. Said, N.I, 2006. Paket Teknologi Pengolahan Air Limbah Rumah Sakit dengan Sistem Biofilter AnaerobAerob. http://ejurnal.bppt.go.id. Diakses pada tanggal 04 Agustus 2015

11. Soeparman dan Suparmin, 2001. Pembuangan Tinja dan Limbah Cair, Kedokteran EGC, Jakarta.

12. Suharto, 2011. Limbah Kimia dalam Pencemaran Udara dan Air, ANDI Yogyakarta, Yogyakarta.

13. Siregar, Sakti A, 2005. Instalasi Pengolahan Air Limbah, Kanisinus, Yogyakarta.

14. Suprihatin dan Suparno, 0, 2013. Teknologi Proses Pengolahan Air, IPB Press, Bogor. 